\title{
Pattern of renal amyloidosis in South Africa
}

\author{
Muhammed Hassen ${ }^{1 *}$ D, William Bates ${ }^{2}$ and Mohammed Rafique Moosa ${ }^{1}$
}

\begin{abstract}
Background: Kidney disease is a serious manifestation of systemic amyloidosis and a major cause of morbidity and mortality. Tuberculosis (TB) occurs up to 27 times more commonly in human immunodeficiency virus (HIV) infected patients and is also an important cause of renal amyloid; there are however no reports of renal amyloidosis in South Africa in the HIV era.

Methods: This was a retrospective record review of cases of amyloidosis diagnosed on renal biopsies at our tertiary referral hospital between January 1985 and December 2016.

Results: Forty-six cases of amyloidosis were identified over the study period. The calculated biopsy prevalence was 1.38 per 100 non-transplant renal biopsies (95\% Confidence Interval 1.02-1.86). AL amyloidosis was identified in 26 (57\%) cases and AA in 20 (43\%). The median age at presentation was 51 years and 52\% of cases were female. Patients with AA amyloidosis were significantly younger compared to their AL counterparts (age 42 years vs. 58 years, $p=<0.001)$ and were all significantly non-white. The main clinical presentation was nephrotic syndrome $(85 \%)$ and $52 \%$ of cases also had a serum creatinine value of greater than $120 \mu \mathrm{mol} / \mathrm{L}$. Of the 20 cases of AA amyloidosis, 12 (60\%) were associated with tuberculosis. HIV infection was noted in only two (10\%) of the 20 AA cases. Median survival after diagnosis was 2 months.
\end{abstract}

Conclusion: Amyloidosis is a rare cause of kidney disease and typically presents with nephrotic syndrome. A similar number of AA and AL types were observed, and outcomes are worse in cases of AA amyloid. While TB remains the major underlying disease in this type, HIV infection was infrequent in cases of AA renal amyloidosis.

Keywords: Amyloidosis, HIV, Tuberculosis, Chronic kidney disease

\section{Background}

Renal manifestation of systemic amyloidosis carries a significant morbidity and mortality, and is most frequently seen either in the setting of chronic inflammation (AA amyloidosis), or plasma cell dyscrasias (AL amyloidosis) [1-5]. Without treatment, amyloidosis associated kidney disease progresses rapidly to end-stage renal disease (ESRD). A recent study reported dialysis dependence within 18 months of diagnosis of AA amyloidosis and mean patient survival of 52.9 months, whilst these outcomes were 36.3 months and 50 months respectively in AL amyloid [4, 6].

Marked differences in the epidemiological patterns of amyloidosis are seen between different countries, highlighting the importance of local data [2, 7-9]. AL amyloidosis is more prevalent in developed countries,

\footnotetext{
* Correspondence: mo.hassen85@gmail.com

${ }^{1}$ Division of Nephrology, Stellenbosch University and Tygerberg Hospital,

Cape Town, South Africa

Full list of author information is available at the end of the article
}

whilst AA amyloidosis is more common in the developing world $[2,7,8,10]$. The developmental status of a particular country, its prevalence of infectious diseases, as well as public health measures implemented to control chronic infections are dynamic factors influencing the prevalence of secondary (AA) amyloidosis over time $[5,11,12]$. Tuberculosis (TB) is a common underlying disease in AA amyloidosis, particularly in developing countries [2, 7, 9]. Underlying human immunodeficiency virus (HIV) infection increases the risk of TB 6 to 27 times compared to those that are not infected [13]. South Africa has amongst the highest rates of both TB and HIV infection in the world; the incident rate of TB was 781 cases per 100, 000 population in 2016 and the estimated HIV prevalence rate was $12.57 \%$ of the total population $[13,14]$. The immunocompromised state rendered by HIV increases the risk of TB disease substantially, with a TB/ HIV co-infection rate in South Africa of 70\% [15].

(c) The Author(s). 2019 Open Access This article is distributed under the terms of the Creative Commons Attribution 4.0 International License (http://creativecommons.org/licenses/by/4.0/), which permits unrestricted use, distribution, and reproduction in any medium, provided you give appropriate credit to the original author(s) and the source, provide a link to the Creative Commons license, and indicate if changes were made. The Creative Commons Public Domain Dedication waiver (http://creativecommons.org/publicdomain/zero/1.0/) applies to the data made available in this article, unless otherwise stated. 
Amyloidosis is generally an uncommon histological finding on renal biopsies of HIV infected patients. Gerntholz et al. [16] identified no cases of amyloidosis among 99 patients and Wearne and Okpechi [17] a single one among 221 South African patients; Wyatt et al. [18] reported one case of amyloidosis among 89 American and as did Nebuloni et al. [19] in 73 Italian subjects. The cases of amyloidosis and HIV infection that have been reported are predominantly in intravenous drug users (IVDUs) [20-22]. Data from the pre-HIV era in South Africa suggest that AA amyloidosis is the most common type of amyloidosis seen and that TB infection is the most frequently associated risk factor [2].

We reviewed all the cases of renal amyloidosis at our institution in the context of the HIV epidemic currently prevailing in South Africa.

\section{Methods}

\section{Study design}

We conducted a retrospective review of consecutive cases of renal amyloidosis.

\section{Setting and study population}

Renal biopsies performed at Tygerberg Academic Hospital between 01 January 1985 and 31 December 2016 were identified using the kidney biopsy register. This register served as the sampling frame and cases of definitive or possible amyloidosis were extracted from this source. Tygerberg Academic Hospital is a tertiary referral hospital that serves about one-half of the population of Western Cape, which was estimated at six and a half million in 2017 [14].

\section{Participants}

All participants aged 13 years and older at renal biopsy, who had a histological diagnosis of renal amyloidosis, as defined by renal biopsy with either apple green birefringence on Congo Red stain and/or amyloid fibrils detected on electron microscopy, were included.

\section{Sampling technique}

Records from the renal biopsy register were reviewed over the 32-year period. All cases diagnosed as definite or possible amyloidosis were evaluated. All renal pathology has been reviewed by a single experienced renal pathologist (WDB). All renal tissue was collected by percutaneous biopsy and evaluated by light microscopy, immunofluorescence and electron microscopy. Renal biopsy material was received fresh and unfixed, evaluated and divided under a dissecting microscope to provide optimal numbers of glomeruli for light and electron microscopy as well as immunofluorescent studies. The ultrastructural material was then fixed in $2.5 \%$ glutaraldehyde in $0.1 \mathrm{M}$ phosphate buffer, while the light microscopy material was fixed in buffered formalin. Material for immunofluorescence was frozen, cryostat sections cut and labeled for IgA, IgG, IgM and C3. Electron microscopy (EM) specimens were post-fixed in osmium tetroxide embedded in Spurr's resin.

For light microscopy, serial two-to-three micron sections were stained with hematoxylin and eosin and other special stains, including Congo Red (Fig. 1).

For all this period, immunohistochemistry for AA amyloidosis was available and performed routinely. Testing for kappa and lambda light chains was carried out via immunohistochemistry for most of the study period, with a few recent cases employing immunofluorescence.

The diagnosis of amyloidosis was confirmed by a positive Congo red staining examined with applegreen birefringence under polarized light. Typical electron microscopic features of randomly disposed, rigid, nonbranching and variably long fibrils were also considered diagnostic.

Case histories were obtained from hospital records and supplemented by relevant laboratory databases. All the diagnoses listed in clinical notes, evidence of treatment of a specific condition (e.g. TB treatment) or pathological confirmation of a disease prior to, as well as 6 months after the date of biopsy findings of amyloidosis, were recorded. Data were analysed and attempts made to determine the type of amyloidosis present if not explicitly stated in the clinical record. This was done considering the clinical history, immunohistochemistry on biopsy, as well as further testing specifically for plasma cell dyscrasias. If a case was indeterminate, it was documented as such. Survival was determined from medical records, hospital registry data or national mortality records.

Demographic data included were age at renal biopsy, ethnicity and gender; clinical data related to presentation and the indication for biopsy; laboratory data were degree of proteinuria (either by 24-h urine collection or estimated from spot urine protein: creatinine ratio), serum creatinine, serum albumin and serum cholesterol as well as HIV antibody testing using ELISA techniques. When multiple entries for the same variable were found, data were captured with preference given in order to the first set of values obtained 1 month before biopsy (presumably taken on admission), the values recorded on the histology report, and lastly any value found from 1 month pre-biopsy to 6 months post biopsy. Case records of the 46 patients were supplemented with additional laboratory data available for 33 of the cases (72\%).

\section{Statistical considerations and sample size}

The sample size was limited by the number of cases identified over the study period. The prevalence of amyloidosis on renal biopsy was calculated by dividing the number of cases of amyloidosis by the total number of adult non- 

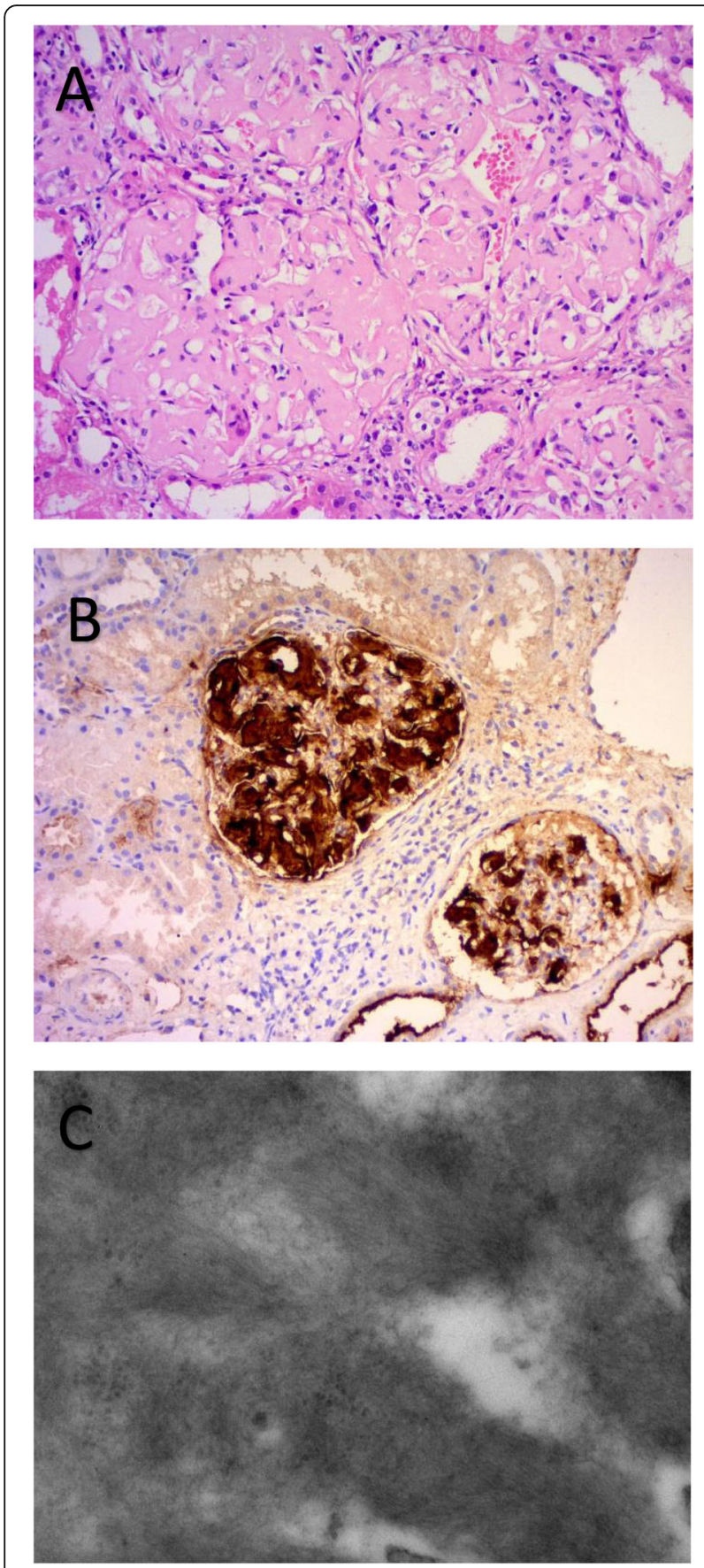

Fig. 1 Histology of renal amyloidosis. a H\&E stain shows extensive effacement of the glomerular architecture by amorphous amyloid. $\mathbf{b}$ The involvement of glomeruli by AA amyloid are revealed by immunohistochemistry using antibody specific for amyloid A protein. c Electron micrograph shows random alignment of amyloid fibrils in the subepithelial zone of a glomerular capillary

transplant biopsies performed over the study period. IBM SPSS version 23 (IBM Corp. Released 2015. IBM SPSS Statistics for Windows, Version 23.0. Armonk, NY: IBM Corp.) was used to analyse the data. Survival was estimated using Kaplan-Meier analysis. Values are reported as medians with inter-quartile ranges (IQR). Non-parametric Mann Whitney tests were used to compare non-normally distributed continuous variables between the two types of amyloidosis. Pearson's chi-square or Fisher's exact tests were used compare categorical variables between the types. A $p$ value $<0.05$ was considered statistically significant.

\section{Results}

Over the 32-year period, 3329 non-transplant renal biopsies were performed and $48(1.4 \%)$ cases of amyloidosis were identified. One patient with amyloidosis on three separate renal biopsies was only counted once. The prevalence of amyloidosis on renal biopsy over the 32-year period was 1.38 per 100 non-transplant renal biopsies. There was a trend to a decline in the biopsy prevalence of all types of amyloidosis over the 32-year period, mainly due to fewer AA cases noted over this time.

The epidemiology, presenting features, laboratory features and survival outcomes are shown (Table 1). The median age at presentation was 51 years (range 21 to 85 ) and 24 of the 46 patients (52\%) were female. The nephrotic syndrome was the commonest presentation in 39 (85\%) patients, followed by renal failure (serum creatinine $>120 \mu \mathrm{mol} / \mathrm{L})$ in $24(52 \%)$.

The cases were classified as AL type (26 cases, $57 \%$ ) and AA (20 cases, 44\%). Screening tests to exclude AL amyloidosis (serum or urine protein electrophoresis) were performed in $45 \%$ of those with AA amyloidosis. Bone marrow examination was performed in 24 of the 26 AL cases. AA amyloidosis patients were younger (median age 42 years, IQR 31-51 years) compared to those with AL disease (median age 59 years, IQR 50 to 66 years). None of the patients with AA amyloid were white; by contrast 7 (27\%) of AL cases were white.

Immunohistochemistry of the biopsy specimen identified 18 (90\%) cases with the final clinico-histopathological diagnosis of AA amyloidosis. The remaining two (10\%) cases were presumed to be of the AA type as the immunohistochemical staining was indeterminate; one had active pulmonary tuberculosis whilst the second had infective endocarditis and HIV infection, with no monoclonal peak detected in the urine or serum. Only one patient identified as having AA on immunohistochemistry of the renal specimen was found to have a clinico-histopathological diagnosis of AL after subsequent investigations. 13 (50\%) cases with the final clinico-histopathological diagnosis of $\mathrm{AL}$ amyloidosis were indeterminate on immunohistochemistry or fluorescence, with 11 cases (42\%) being correctly identified. This diagnostic uncertainty was primarily due to high background staining, likely from contaminating serum proteins [23]. The remaining cases all had a detectable monoclonal peak in serum, urine or bone marrow 
Table 1 Characteristics of 46 cases of renal amyloidosis

\begin{tabular}{|c|c|c|c|c|}
\hline & AA & $\mathrm{AL}$ & $p$ value & Total \\
\hline Number of cases, $n(\%)$ & $20(43)$ & $26(57)$ & & $46(100)$ \\
\hline Age (years) at diagnosis, median (IQR) & $42(31-51)$ & $58(50-66)$ & $<0.001$ & $51(41-62)$ \\
\hline Sex, $n(\%)$ & & & 0.74 & \\
\hline Male & $9(45)$ & $13(50)$ & & $22(48)$ \\
\hline Female & $11(55)$ & $13(50)$ & & $24(52)$ \\
\hline Ethnicity, n (\%) & & & 0.03 & \\
\hline African & $10(50)$ & $7(27)$ & & $17(37)$ \\
\hline White & 0 & $7(27)$ & & $7(15)$ \\
\hline Mixed race & $10(50)$ & $12(46)$ & & $22(48)$ \\
\hline Presentation, $n(\%)$ & & & 0.59 & \\
\hline Nephrotic syndrome & $8(40)$ & $14(54)$ & & $22(48)$ \\
\hline $\begin{array}{l}\text { Nephrotic syndrome and renal failure } \\
\text { (serum creatinine }>120 \mu \mathrm{mol} / \mathrm{L} \text { ) }\end{array}$ & $9(45)$ & $8(31)$ & & $17(37)$ \\
\hline $\begin{array}{l}\text { Renal failure without nephrotic } \\
\text { syndrome }\end{array}$ & $3(15)$ & $4(15)$ & & $7(15)$ \\
\hline \multicolumn{5}{|l|}{ Laboratory Features, median (IQR) } \\
\hline Serum creatinine $(\mu \mathrm{mol} / \mathrm{L})$ & $276(68.5-882.5)$ & $88.5(82-244)$ & 0.52 & $172(81-385)$ \\
\hline Degree of proteinuria (g/day) & $9.7(5.1-17.6)$ & $6.2(4.8-8.2)$ & 0.19 & $6.76(4.9-12.0)$ \\
\hline Serum albumin (g/L) & $18(16.0-20)$ & $23.5(18-31)$ & 0.03 & $19(16-29)$ \\
\hline Serum total cholesterol $(\mathrm{mmol} / \mathrm{L}))$ & $6.12(5.14-7.8)$ & $8.80(6.60-12.17)$ & 0.01 & $7.45(5.9-11.6)$ \\
\hline HIV Status, $n(\%)$ & & & 0.15 & \\
\hline Positive & $2(10)$ & $0(0)$ & & $2(4)$ \\
\hline Negative & $15(75)$ & $18(69)$ & & $33(72)$ \\
\hline Unknown & $3(15)$ & $8(31)$ & & $11(24 \%)$ \\
\hline \multicolumn{5}{|l|}{ Outcomes } \\
\hline $\begin{array}{l}\text { Survival after diagnosis (months), } \\
\text { median (IQR) }\end{array}$ & $1(0.75-1.25)$ & $9(1.5-15)$ & 0.02 & $2(1-10)$ \\
\hline
\end{tabular}

Abbreviations: AA Secondary amyloidosis, AL Primary amyloidosis, HIV Human immunodeficiency virus, IQR interquartile range

analysis and usually no associated predisposing cause for AA amyloidosis on clinical grounds.

Serum albumin was significantly lower in cases with AA amyloidosis (18 vs. $23.5 \mathrm{~g} / \mathrm{L}, p=0.03$ ) and median serum creatinine as well as magnitude of proteinuria was higher in AA compared to AL amyloidosis (serum creatinine 276 vs. $88 \mu \mathrm{mol} / \mathrm{L}$, proteinuria 9.7 vs. $6.12 \mathrm{~g} /$ $24 \mathrm{~h})$ but failed to attain statistical significance.

Of the 20 cases of AA amyloidosis, 12 (60\%) were associated with pulmonary TB. Of these 12, three also had bronchiectasis and one patient had active TB as well two other chronic infections (bronchiectasis and bilharzia). Two cases of AA amyloid had no known associations, although both patients had a history of pulmonary TB 10 to 15 years prior to the diagnosis of amyloidosis; the remaining associated conditions in AA amyloidosis are shown (Fig. 2). None of the cases of AA amyloidosis were known intravenous drug users (IVDUs) or had hepatitis B or $\mathrm{C}$ infection.
Of the 26 patients with AL amyloid, 12 (42.2\%) were diagnosed with multiple myeloma and were treated with steroids, and either melphalan or cyclophosphamide. Of the remaining 14 patients with AL amyloid four received melphalan and steroids; the remainder received no specific therapy. In patients with AA amyloidosis treatment was primarily of the underlying disease as identified. Both HIV-infected patients were anti-retroviral therapy naive at presentation.

Other organ involvement occurred mostly in patients with AL amyloid: a single patient had amyloid deposits on colonic biopsy and four on the bone marrow biopsy; single patients with AL amyloid had hepatosplenomegaly, macroglossia; and suspicious thyroid lesions on radioisotope scan; two patients with multiple myeloma were diagnosed with carpal tunnel syndrome and three patients had echocardiographic findings suspicious of cardiac involvement. Interestingly, none of the patients with AA amyloid manifested systemic disease at presentation. 


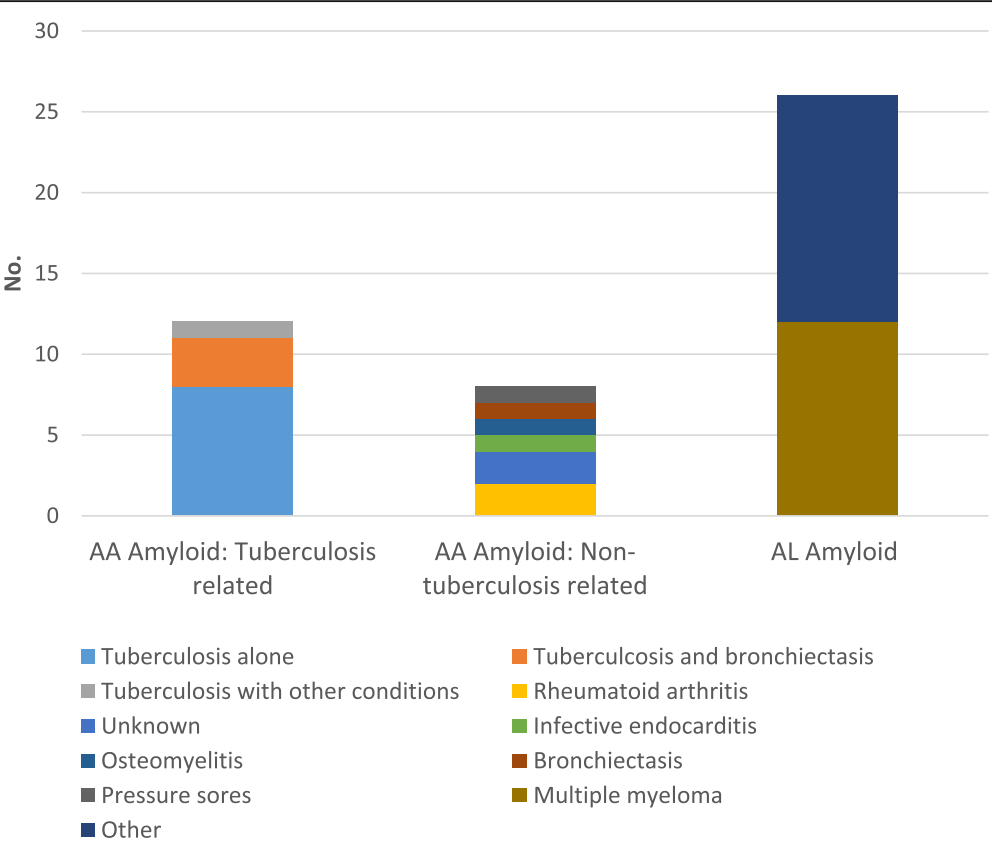

Fig. 2 Causes of $A A$ and $A L$ amyloidosis

HIV status was known in 35 (76\%) patients with no test results available before 1992. HIV infection was noted in only two patients (4\%); both cases were of the AA type. One of these patients had infective endocarditis and the other had no identifiable association although the patient did have pulmonary TB 14 years prior to biopsy. By comparison, in the total 3329 renal biopsies done over the study period, 481 biopsies were in patients with confirmed HIV, with a total biopsy prevalence for HIV of $14.4 \%$. Analysis of data exclusively in the period after the introduction of HIV testing in 1992 yields a biopsy prevalence of HIV of 5\% in the amyloid cohort, and $17 \%$ in the overall biopsy cohort.

Survival data were available for 25 (54\%) patients (Fig. 3). The median survival was 2 months after diagnosis with a range of 0 to 249 months. A significantly worse outcome was found in cases of AA amyloidosis, with a median survival of 1 month after diagnosis as compared to 9 months in AL amyloidosis $(p=0.02)$.

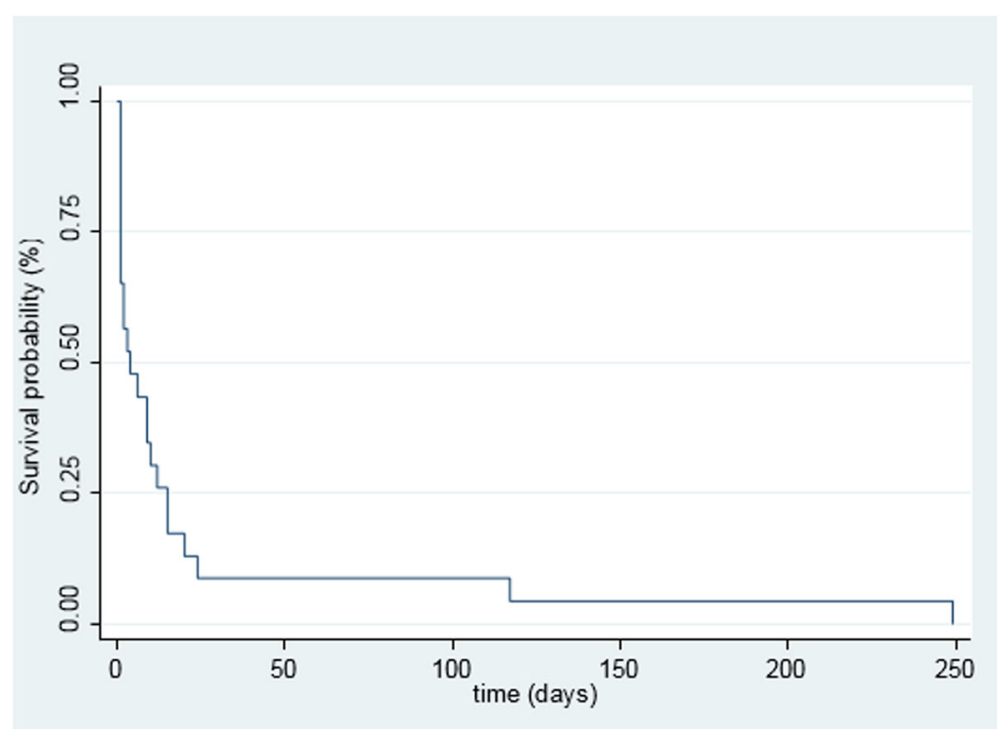

Fig. 3 Kaplan-Meier estimate of survival of patients with amyloid $(N=25)$ 


\section{Discussion}

Amyloidosis is a rare cause of kidney disease accounting for less than $2 \%$ of all biopsied patients and is most commonly associated with TB in the South African setting. It is most likely to present with nephrotic syndrome. A similar number of AA and AL cases were observed and outcomes were poor. AA amyloidosis patients were noted to be younger compared to AL patients, usually had an identifiable disease associated with amyloidosis established on presentation and were all African or mixed ethnicity. HIV infection in our community appeared not to have a discernible impact on the prevalence of amyloidosis in South Africa in our study.

These observations are consistent with other studies. The high proportion of TB associated cases in AA amyloidosis (60\%) was higher than the $40 \%$ reported by Mody in 1984. This likely represents the increasing incidence of TB over the past three decades [24].

The total number of AL cases slightly exceeds those of AA which is unusual for a developing country. This difference was small but difficult to explain, especially considering the high levels of $\mathrm{TB}$ noted in South Africa. A comparison of the associated diseases of AA amyloidosis in different regions of the world is shown (Fig. 4).

Based on the high prevalence of HIV in our setting of $12.6 \%$, we had expected to see many more cases with HIV (Fig. 5). A possible explanation for this is sampling bias. The clinical presentation of HIV associated nephropathy (HIVAN) with nephrotic range proteinuria, renal failure and large kidneys on ultrasound is very similar to that of amyloidosis. However, the standard practice of our institution is to perform a renal biopsy in all cases of suspected HIVAN if not contra-indicated, making this explanation unlikely.

HIV infection has been associated with both AA and AL amyloidosis in case reports [21, 22, 26-28]. Most cases of AA amyloidosis have been reported in IVDUs, fewer cases with visceral leishmaniasis and multicentric Castleman's disease, and to our knowledge, only 1 case report exists of HIV, amyloidosis and presumed TB coexisting in a known IVDU [20-22, 29, 30].

Of the two patients in our study with HIV, one had infective endocarditis which was thought to be directly associated with amyloidosis, whilst the other had no other clinical manifestation apart from HIV infection which could be directly associated with amyloidosis. None of the cases in our series were known IVDUs. Based on a high estimated prevalence of IVDUs in our population [31], this is likely a result of sampling bias in a single centre study.

The association between amyloidosis and HIV is plausible, as higher levels of serum amyloid A (SAA) protein - the acute phase reactant protein from which amyloid fibrils are derived in AA amyloidosis - has been documented in HIV positive individuals [26, 32, 33]. However, substance abuse without HIV infection has also been associated with higher levels of SAA. Samikkannu et al. [28] reported higher levels of SAA in IVDUs, alcoholics and those abusing methamphetamines, independent of underlying HIV infection.

Case series of amyloidosis have revealed discrepant prevalence of HIV in renal amyloidosis. Jung et al. [21] found 12 cases of renal amyloidosis in 24 renal biopsies of IVDUs in a single metropolitan area in Germany, with a significantly higher HIV infection rate (8 cases) in those with amyloidosis than those without amyloidosis ( 2 cases of HIV). This high percentage of amyloidosis found in this cohort of IVDUs (50\% of cases) is much higher than reported in other studies. A Portuguese study of 19 IVDUs, of 3 who also had HIV, reported only a single case of amyloidosis. Similar results were found in an American study of 14 HIV and hepatitis C co-infected IVDUs, where no cases of amyloidosis were found $[34,35]$.

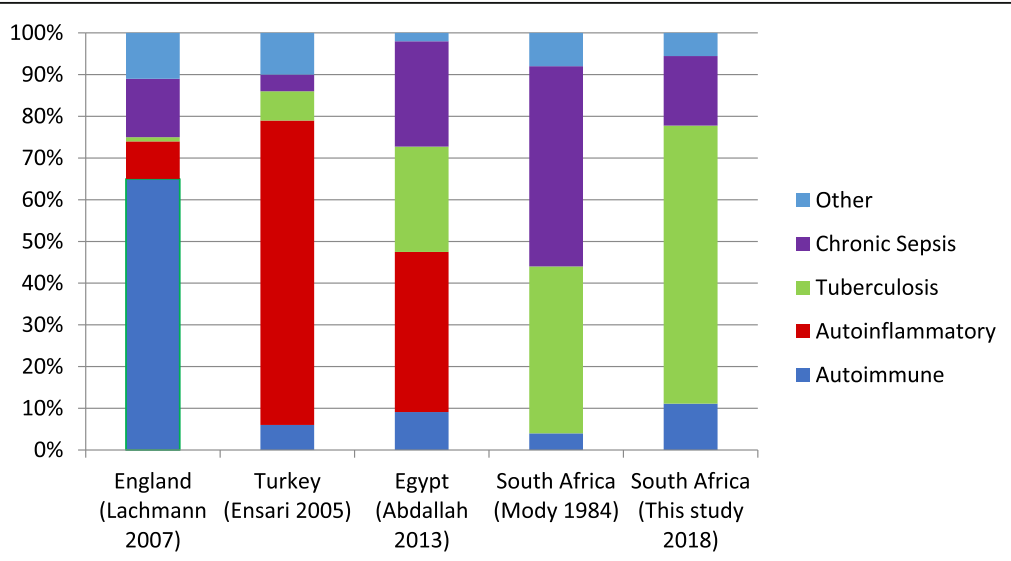

Fig. 4 Proportion of diseases associated with AA amyloidosis in different countries [2, 7-9] 


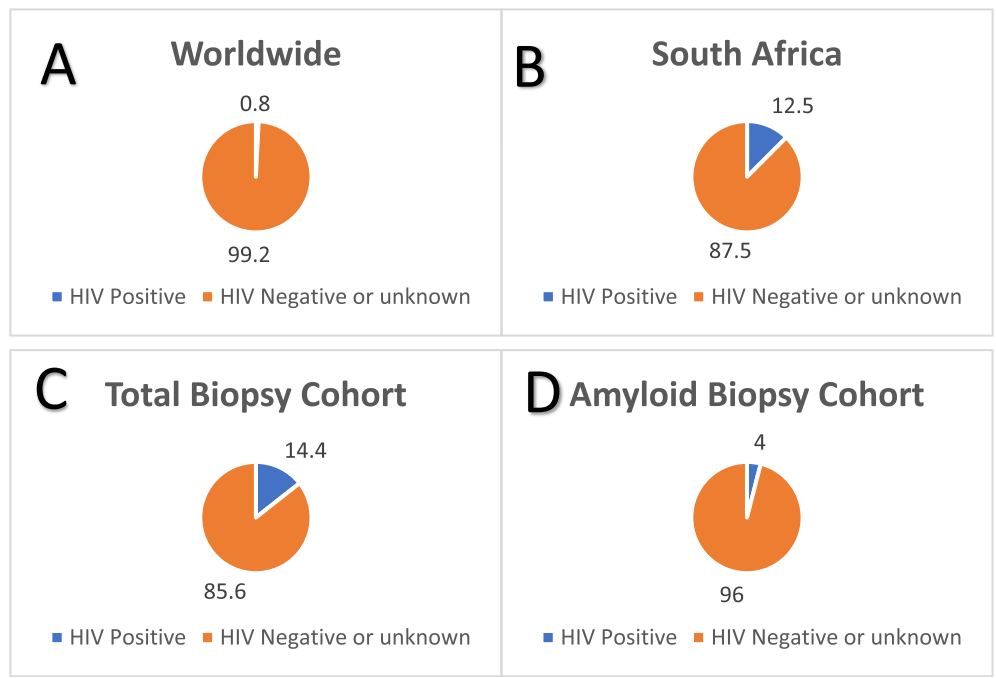

Fig. 5 Comparison of HIV prevalence in populations (a and b) $[14,25]$ and within our biopsy cohort (c and $\mathbf{d}$ )

This discrepancy in the prevalence of HIV in amyloidosis suggests that other confounding factors may be present. Miranda et al. [20] postulate that these discrepancies are largely based on geographical peculiarities and point to skin and soft tissue infection in IVDUs being the driving factor for amyloid deposition, not HIV or hepatitis B or C. Our data, with a low HIV infection rate and no IVDU cases, would support this theory.

Similar to HIV and rather unsurprisingly, TB has also been found to have high levels of SAA [36]. However, we noted no cases of TB (the major predisposition for AA amyloidosis in our study) and HIV co-infection, a finding which is difficult to explain considering the high levels of SAA reported in both conditions together with the 70\% HIV/TB co-infection rate found in South Africa. These findings may be corroborated from reviewing the literature, as no case has been described of definitive $T B$ alone causing AA amyloidosis in an HIV infected individual.

Thus, the association between amyloidosis and HIV infection is complex and not well understood. Husebekk et al. [37] suggested in 1986 that amyloidosis may not be found in HIV as its course progressed rapidly to demise. However, survival of patients with HIV has improved dramatically since then and this factor alone cannot explain the low frequency of HIV infection amongst our cases. We put forward two novel suggestions about the link between HIV and amyloidosis: firstly that AA amyloidosis may protect an individual from HIV infection as high levels of SAA usually seen in AA amyloidosis have been found to confer some resistance to HIV infection after exposure to the virus [38, 39]; secondly that HIV may even be protective against amyloidosis through impairment of the complex process of fibrillogenesis [40]. Immune dysregulation in HIV, manifesting with alterations in $\mathrm{CD}_{4}^{+} \mathrm{T}$ helper cell subsets' function and quantity, may be a mechanism of this impairment of fibrillogenesis [41]. No direct evidence exists to support the second theory and further studies are needed to clarify this association.

The high mortality rate in our patient reflects the advanced state of disease at presentation due to delay in help seeking and/or diagnosis. The exact cause of death was not always known. The survival of a single patient for 249 months in AA amyloidosis due to pulmonary TB suggests that adequate treatment in certain individuals may induce a remission in this disease, but factors related to this could not be identified in our study.

The strengths of this study lie in the extended period over which data were available, the use of various specialised tests to confirm the diagnosis and type of amyloidosis (electron microscopy and immunohistochemistry on biopsy) and the various databases which were searched to obtain and confirm data over this period. The high prevalence of HIV in our setting provided a unique environment to observe the association between HIV and amyloidosis. The weaknesses are primarily related to the nature of retrospective case series which are reliant on completeness of data and observations made at the time of presentation. The inability to test for genetic causes of renal amyloidosis may have led to a misclassification of the type of amyloidosis, although these hereditary causes are uncommon [42]. Due to the small numbers in our study, further statistical analysis to substantiate the impact of HIV on amyloidosis was limited.

\section{Conclusion}

Amyloidosis is a rare cause of kidney disease in our setting with poor outcomes. A similar number of AA and 
AL cases were observed, and a nephrotic presentation is characteristic. TB is the usual association in AA amyloidosis and highlights its burden on health in South Africa. HIV was not found to have a discernible impact in the prevalence of amyloidosis in South Africa in our study and our hypothesis that HIV infection and amyloidosis may be mutually protective needs further study.

\section{Abbreviations}

AA: Amyloid A or secondary amyloidosis; AL: Light chain or primary amyloidosis; HIV: Human Immunodeficiency Virus; IE: Infective endocarditis; IHC: Immunohistochemistry; IQR: Inter quartile range; IVDU: Intravenous drug user; JIA: Juvenile inflammatory arthritis; RA: Rheumatoid arthritis; TB: Tuberculosis

\section{Acknowledgements}

The Biostatistics Division at Stellenbosch University assisted in statistical analysis of the data.

\section{Authors' contributions}

Conception of the study: WDB, MRM; Data collection: MH, WDB; Data analysis and interpretation: $\mathrm{MH}, \mathrm{WDB}, \mathrm{MRM}$; Drafting of the manuscript: $\mathrm{MH}$; Statistical analysis: Biostatistics Unit, Stellenbosch University; Critical revision of the manuscript for important content: MRM; Person in charge of study: $\mathrm{MH}$. All authors read and approved the final manuscript.

\section{Funding}

This study was self-funded.

\section{Availability of data and materials}

The datasets used and/or analysed during the current study are available from the corresponding author on reasonable request.

\section{Ethics approval and consent to participate}

Approval was obtained from the Human Research Ethics Committee (HREC) of Stellenbosch University (protocol number S15/02/020) and the Chief Executive Officer of Tygerberg Hospital to conduct this study. In view of the retrospective nature of the study, waiver of patient consent was approved by the HREC.

\section{Consent for publication}

Not Applicable.

\section{Competing interests}

The authors declare that they have no competing interests. The results presented in this article have not been published previously in whole or part, except in abstract format.

\section{Author details}

'Division of Nephrology, Stellenbosch University and Tygerberg Hospital, Cape Town, South Africa. ${ }^{2}$ Department of Anatomical Pathology,

Stellenbosch University and Tygerberg Hospital, Cape Town, South Africa.

Received: 18 January 2019 Accepted: 28 October 2019

Published online: 09 November 2019

\section{References}

1. Dember LM. Amyloidosis-associated kidney disease. J Am Soc Nephrol. 2006;17(12):3458-71.

2. Mody G, Bowen R, Meyers OL. Amyloidosis at Groote Schuur Hospital, Cape Town. South African Med J. 1984;66(2):47-9.

3. Real de Asúa D, Costa R, Contreras MM, Gutiérrez Á, Filigghedu MT, Armas M. Clinical characteristics of the patients with systemic amyloidosis in 20002010. Rev Clínica Española. 2013;213(4):186-93.

4. Joss N, McLaughlin K, Simpson K, Boulton-Jones JM. Presentation, survival and prognostic markers in AA amyloidosis. Qjm. 2000;93(8):535-42.

5. Connolly JO, Gillmore JD, Lachmann HJ, Davenport A, Hawkins PN, Woolfson RG. Renal amyloidosis in intravenous drug users. Qjm. 2006:99(11): 737-42
6. Huang X, Wang Q, Jiang S, Chen W, Zeng C, Liu Z. The clinical features and outcomes of systemic AL amyloidosis: a cohort of 231 Chinese patients. Clin Kidney J. 2015;8(1):120-6.

7. Lachmann HJ, Goodman HJB, Gilbertson JA, Gallimore JR, Sabin CA Gillmore JD, et al. Natural history and outcome in systemic AA amyloidosis. N Engl J Med. 2007;356(23):2361-71.

8. Ensari C, Ensari A, Tümer N, Ertug E. Clinicopathological and epidemiological analysis of amyloidosis in Turkish patients. Nephrol Dial Transplant. 2005; 20(8):1721-5.

9. Abdallah EWE. Incidence and clinical outcome of renal amyloidosis: a retrospective study. Saudi J Kidney Dis Transpl. 2013;24(5):950-8.

10. Real de Asúa D, Costa R, Galván JM, Filigheddu MT, Trujillo D, Cadiñanos J. Systemic AA amyloidosis: epidemiology, diagnosis, and management. Clin Epidemiol. 2014;6(October):369-77.

11. Lane T, Pinney JH, Gilbertson JA, Hutt DF, Rowczenio DM, Mahmood S, et al. Changing epidemiology of AA amyloidosis: clinical observations over 25 years at a single national referral Centre. Amyloid. 2017;24(3):162-6.

12. Panizo N, Rivera F, López-Gómez JM. Spanish registry of glomerulonephritis. Decreasing incidence of AA amyloidosis in Spain. Eur J Clin Investig. 2013; 43(8):767-73.

13. World Health Organization. Global Tuberculosis Report. 2017.

14. Statistics South Africa. Mortality and causes of death in South Africa, 2015 findings from death notification. Statistical Release P0309.3. Pretoria: Stats SA; 2017.

15. Abdool Karim SS, Churchyard GJ, Abdool Karim Q, Lawn SD. HIV infection and tuberculosis in South Africa: an urgent need to escalate the public health response. Lancet. 2009;374(9693):921-33.

16. Gerntholtz TE, Goetsch SJW, Katz I. HIV-related nephropathy: a south African perspective. Kidney Int. 2006;69(10):1885-91

17. Wearne N, Okpechi IG. HIV-associated renal disease - an overview. Clin Nephrol. 2016;86 (2016)(13):41-7

18. Wyatt CM, Morgello S, Katz-Malamed R, Wei C, Klotman ME, Klotman PE, et al. The spectrum of kidney disease in patients with AIDS in the era of antiretroviral therapy. Kidney Int. 2009;75(4):428-34.

19. Nebuloni M, Barbiano di Belgiojoso G, Genderini A, Tosoni A, LN R, et al Glomerular lesions in HIV-positive patients: a 20-year biopsy experience from northern Italy. Clin Nephrol. 2009 Jul;72(1):38-45.

20. Miranda BH, Connolly JO, Burns AP. Secondary amyloidosis in a needle phobic intra-venous drug user. Amyloid. 2007;14(3):255-8.

21. Jung $O$, Haack HS, Buettner M, Betz C, Stephan C, Gruetzmacher P, et al. Renal AA-amyloidosis in intravenous drug users - a role for HIV-infection? BMC Nephrol. 2012;13(1):151.

22. Silva GEB, Costa RS, Dantas M. Amiloidose secundária associada à tuberculose numa biópsia renal. Rev Soc Bras Med Trop. 2011:44(6):797.

23. Jennette JC, Olsen JL, Silva FG, D’Agati VD. Renal Diseases Associated with Plasma Cell Dyscrasias, Amyloidoses, and Waldenström Macroglobulinemia. In: Heptinstall's Pathology of the Kidney. 7th. Philadelphia: Lippincott Williams \& Wilkin; 2015. 981.

24. World Health Organization. Global Tuberculosis Report 2012. 2012

25. UNAIDS. AIDSinfo [Internet]. AIDSinfo. 2016. Available from: http://aidsinfo unaids.org/. [cited 2018 Aug 26]

26. Cozzi PJ, Abu-Jawdeh GM, Green RM, Green D. Amyloidosis in association with human immunodeficiency virus infection. Clin Infect Dis. 1992;14(1):189-91.

27. Denman J, Manavi K, Cook M. Lenalidomide as a treatment for relapsed AL amyloidosis in an HIV-positive patient. Int J STD AIDS. 2017;28(10):1045-7.

28. Coelho S, Fernandes A, Soares E, Valério P, Farinha A, Natário A, et al. Amyloidosis related to HIV - An unusual cause of nephrotic syndrome in HIV patients. Portuguese Journal of Nephrology \& Hypertension 2017; 31(September):207-11.

29. de Vallière S, Mary C, Joneberg JE, Rotman S, Bullani R, Greub G, et al. AAamyloidosis caused by visceral leishmaniasis in a human immunodeficiency virus-infected patient. Am J Trop Med Hyg. 2009:81(2):209-12.

30. El Karoui $K$, Vuiblet $V$, Dion D, Izzedine $H$, Guitard J, Frimat $L$, et al. Renal involvement in Castleman disease. Nephrol Dial Transplant. 2011; 26(2):599-609.

31. Mathers BM, Degenhardt L, Phillips B, Wiessing L, Hickman M, Strathdee SA et al. Global epidemiology of injecting drug use and HIV among people who inject drugs: a systematic review. Lancet. 2008:372(9651):1733-45.

32. Fuster D, Cheng DM, Quinn EK, Armah KA, Saitz R, Freiberg MS, et al. Inflammatory cytokines and mortality in a cohort of HIV-infected adults with alcohol problems. 2015;28(7):1059-64 
33. Samikkannu T, Rao KVK, Arias AY, Kalaichezian A, Sagar V, Yoo C, et al. HIV infection and drugs of abuse: role of acute phase proteins. J Neuroinflammation. 2013;10(1):113.

34. do Sameiro Faria M, Sampaio S, Faria V, Carvalho E. Nephropathy associated with heroin abuse in Caucasian patients. Nephrol Dial Transplant. 2003; 18(11):2308-13.

35. Cheng JT, Anderson HL, Markowitz GS, Appel GB, Pogue VA, D'Agati VD. Hepatitis $C$ virus-associated glomerular disease in patients with human immunodeficiency virus coinfection. J Am Soc Nephrol. 1999;10(7):1566-74.

36. Jiang $T$ T, Shi LY, Wei LL, Li X, Yang S, Wang C, et al. Serum amyloid A, protein $Z$, and $C 4 b$-binding protein $\beta$ chain as new potential biomarkers for pulmonary tuberculosis. PLoS One. 2017;12(3):1-20

37. Husebekk A, Permin H, Husby G. Serum amyloid protein A (SAA): an indicator of inflammation in AIDS and AIDS-related complex (ARC). Scand J Infect Dis. 1986;18(5):389-94.

38. Biasin M, Clerici M, Piacentini L. Innate immunity in resistance to HIV infection. J Infect Dis. 2010;202(Suppl):S361-5.

39. Kramer HB, Lavender KJ, Qin L, Stacey AR, Liu MKP, di Gleria K, et al. Elevation of intact and proteolytic fragments of acute phase proteins constitutes the earliest systemic antiviral response in HIV-1 infection. PLoS Pathog. 2010;6(5):1-12.

40. Rochet J, Lansbury PT Jr. Amyloid fibrillogenesis : themes and variations. Curr Opin Struct Biol. 2000;10:60-8.

41. Reuter MA, Pombo C, Betts MR. Cytokine production and dysregulation in HIV pathogenesis: lessons for development of therapeutics and vaccines. Cytokine Growth Factor Rev. 2012;23(4-5):181-91.

42. Lachmann HJ, Booth DR, Booth SE, Bybee A, Gilbertson JA, Gillmore JD, et al. Misdiagnosis of hereditary amyloidosis as AL (primary) amyloidosis. N Engl J Med. 2002;346(23):1786-91.

\section{Publisher's Note}

Springer Nature remains neutral with regard to jurisdictional claims in published maps and institutional affiliations.

Ready to submit your research? Choose BMC and benefit from:

- fast, convenient online submission

- thorough peer review by experienced researchers in your field

- rapid publication on acceptance

- support for research data, including large and complex data types

- gold Open Access which fosters wider collaboration and increased citations

- maximum visibility for your research: over $100 \mathrm{M}$ website views per year

At $\mathrm{BMC}$, research is always in progress.

Learn more biomedcentral.com/submissions 